Supporting material for:

\title{
Multi-scheme chemical ionization inlet (MION) for fast switching of reagent ion chemistry in atmospheric pressure chemical ionization mass spectrometry (CIMS) applications
}

\author{
Authors: Matti P. Rissanen ${ }^{1,2}$, Jyri Mikkilä ${ }^{3}$, Siddharth Iyer $^{4}$, Jani Hakala ${ }^{3}$ \\ ${ }^{1}$ Department of Physics and Institute for Atmospheric and Earth System Research, University of Helsinki, Helsinki, \\ Finland \\ ${ }^{2}$ Aerosol Physics Laboratory, Physics Unit, Faculty of Engineering and Natural Sciences, Tampere University, \\ Tampere, Finland \\ ${ }^{3}$ Karsa Ltd., A. I. Virtasen aukio 1, 00560 Helsinki, Finland \\ ${ }^{4}$ Department of Chemistry and Institute for Atmospheric and Earth System Research, University of Helsinki, Helsinki, \\ Finland
}

Correspondence to: Matti P. Rissanen (matti.rissanen@tuni.fi), Jani Hakala (jani.hakala@karsa.fi)

S1 Abstract - description of the supporting material

This Supporting Information material is intended to clarify and extend the analysis presented in the manuscript text and includes sections S1-S6: S1 Abstract - description of the supporting material, S2 Experimental setup and conditions, S3 Ion signal to concentration conversion, S4 Calibration measurement, S5 Product distributions - specific reaction products, S6 Organic ion peaks devoid of the reagent ion. In addition, this material includes Supporting Figures S1-S3 showing example spectra obtained with the MION. 


\section{S2 Experimental setup and conditions}

All experiments were performed in tubular flow reactors under ambient conditions, at about $293 \mathrm{~K}$ and 1 bar pressure of air. Two flow reactors were used to vary the reaction time with a constant 20 liters-per-minute (lpm) inlet flow rate to the MION. A $2.44 \mathrm{~cm}$ inner diameter (i.d.) and $80 \mathrm{~cm}$ length, and $7.7 \mathrm{~cm}$ i.d. and $120 \mathrm{~cm}$ length reactors were utilized, which allowed for reaction times of around 2 and 10 seconds. Cyclohexene ( $\geq 99 \%$ Sigma-Aldrich) and $\alpha-$ pinene (98\% Sigma-Aldrich) were obtained either by bubbling through a liquid reservoir or from self-made, premixed gas cylinders, embedded in $\mathrm{N}_{2}$. The hydrocarbon precursor was turbulently mixed with the bath gas and ozone few centimeters upstream of the flow reactor. In most of the experiments the hydrocarbon precursor concentrations utilized were close to 100 parts-per-billion ( $\mathrm{ppb}$ ) but were also varied to inspect the concentration dependence of the detection of the current inlet design (see for example manuscript Figure 5). The oxidant ozone $\left(\mathrm{O}_{3}\right)$ flow was kept constant, resulting at about $50 \mathrm{ppb}$ concentration in the reactor, and was produced by a commercial $\mathrm{O}_{3}$-generator (UVP, SOG2), and quantified by an ozone analyzer (Thermo Scientific model 49i). All the gas flow rates were regulated by calibrated mass flow controllers (Bürkert T8742 and MKS GM100A). The mass spectra were obtained with a chemical ionization atmospheric pressure interface time-of-flight mass spectrometer (CI-APi-ToF, Tofwerk).

\section{S3 Ion signal to concentration conversion}

The measured raw ion signals were converted into concentrations by normalizing them with the reagent ion current, i.e., dividing the measured ion signals by the amount of available charge carriers, and multiplying them by a calibration factor determined separately. For the $\mathrm{NO}_{3}^{-}$reagent ion mode the measured ion signals [S] are divided by $\Sigma\left[\left(\mathrm{HNO}_{3}\right)_{\mathrm{x}} \mathrm{NO}_{3}{ }^{-}\right]$, where $\mathrm{x}=0-3$, to account for the most prominent reagent ion adducts (equation S1; see Figure S1 for reagent ion spectra). In the $\mathrm{Br}^{-}$case the charge carrier is solely $\mathrm{Br}^{-}$(or potentially $\mathrm{Br}^{-}+\mathrm{Br}^{*} \mathrm{H}_{2} \mathrm{O}^{-}$). These normalized signals are then further multiplied with a ion-specific calibration factor $\left(C_{H 2 S O 4 / N O 3-B r}\right.$, see below). The conversion procedure can be depicted by equation (S1):

$[$ Product $]=C_{\mathrm{H} 2 \mathrm{SO} 4 / \mathrm{NO}_{3}-} \frac{[\mathrm{S}]}{\Sigma\left[\left(\mathrm{HNO}_{3}\right)_{n} \times \mathrm{NO}_{3}^{-}\right]}, \quad x=0-3$

\section{S4 Calibration measurement}

The ion modes of the MION were independently calibrated against photochemically produced sulfuric acid (SA) (Kürten et al., 2012), which has been the general method for calibrating $\mathrm{NO}_{3}{ }^{-}$based CI-APi-ToF response to highlyoxidized multifunctional product (=HOM) detection (e.g., Ehn et al., 2014; Rissanen et al., 2014; Jokinen et al., 2015) and bases on the assumption that SA and HOM are both charged with collision frequency in the $\mathrm{NO}_{3}{ }^{-} \mathrm{CIMS}($ Ehn et al., 2014). Manuscript Figure 2 showed the obtained calibration plots, in which the measured and normalized $\mathrm{H}_{2} \mathrm{SO}_{4}$ signals were compared to values determined by a simulation of a set of reactions describing the $\mathrm{OH}_{\text {initiated }} \mathrm{SO}_{2}$ photo-oxidation, and the relevant gas motion within the tubular CIMS inlet. The intensity of the light source was determined in separate actinometry measurements and the $[\mathrm{OH}]$ generated by $\mathrm{H}_{2} \mathrm{O}$ photolysis at $185 \mathrm{~nm}$ was corrected for reactive and diffusional loss, as was done also for other reactive species in the mechanism. The whole SA calibration procedure is described in detail in Kürten et al., 2012.

\section{S5 Product distributions - specific reaction products}

Figure $\mathrm{S} 1$ shows examples of $\mathrm{NO}_{3}{ }^{-}$and $\mathrm{Br}^{-}$reagent ion distributions obtained with the MION setup. The top panel shows the full mass spectrum with reagent, monomer and dimer mass ranges indicated by dotted rectangles. The bottom panel shows a zoom into the reagent ion mass range and the inset in the bromide spectrum shows the detected $\mathrm{HO}_{2}$ and $\mathrm{H}_{2} \mathrm{O}_{2}$ adducts with $\mathrm{Br}^{-}$. The mass axis of the $\mathrm{Br}^{-}$spectrum has been displaced by 17 Th to position the same product compositions on top of each other. 

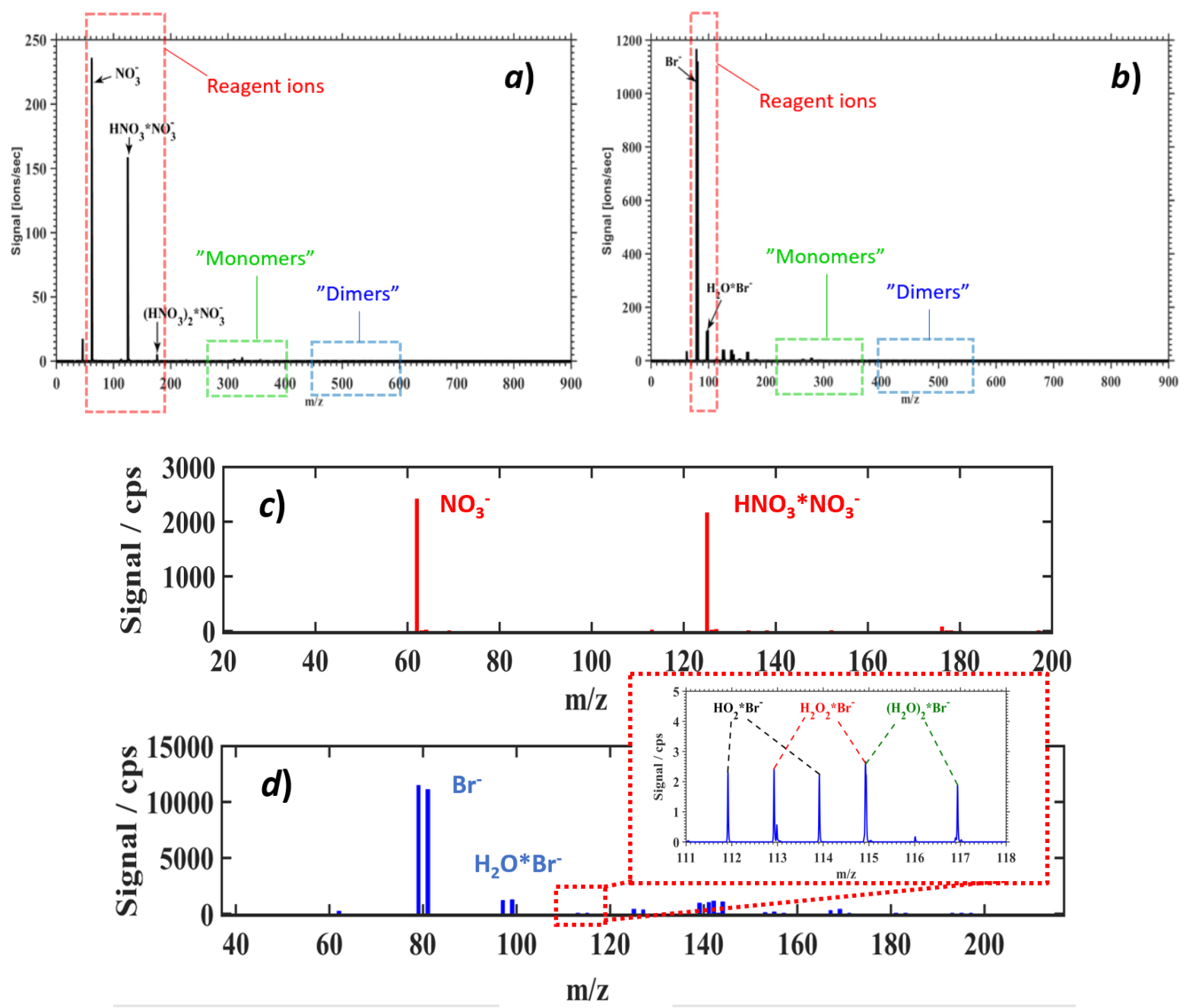

Figure $\mathrm{S1} \boldsymbol{a}$ ) $\mathrm{NO}_{3}^{-}$(nitrate) and $\boldsymbol{b}$ ) $\mathrm{Br}^{-}$(bromide) spectra recorded during an $\alpha$-pinene ozonolysis experiment. Specific regions of the spectra associated with denser populations of product peaks have been labelled, and correspond to reagent ions (red), monomers (green), and dimers (blue). c) Shows the nitrate, and $\boldsymbol{d}$ ) the bromide reagent ion spectrum. Also shown in the inset of figure d) are a few product peaks measured with $\mathrm{Br}$ : hydroperoxy radical $\left(\mathrm{HO}_{2} * \mathrm{Br}^{-}\right)$, hydrogen peroxide $\left(\mathrm{H}_{2} \mathrm{O}_{2} * \mathrm{Br}^{-}\right)$and a water dimer adduct $\left(\mathrm{H}_{2} \mathrm{O}\right)_{2} * \mathrm{Br}^{-}$.

In Figure S2 the cyclohexene HOM distribution obtained with both ion modes is presented analogously to the manuscript Figure 4 of $\alpha$-pinene product distribution. The mass axis of the $\mathrm{Br}^{-}$has again been displaced by $17 \mathrm{Th}$ to position the same product compositions on top of each other. 

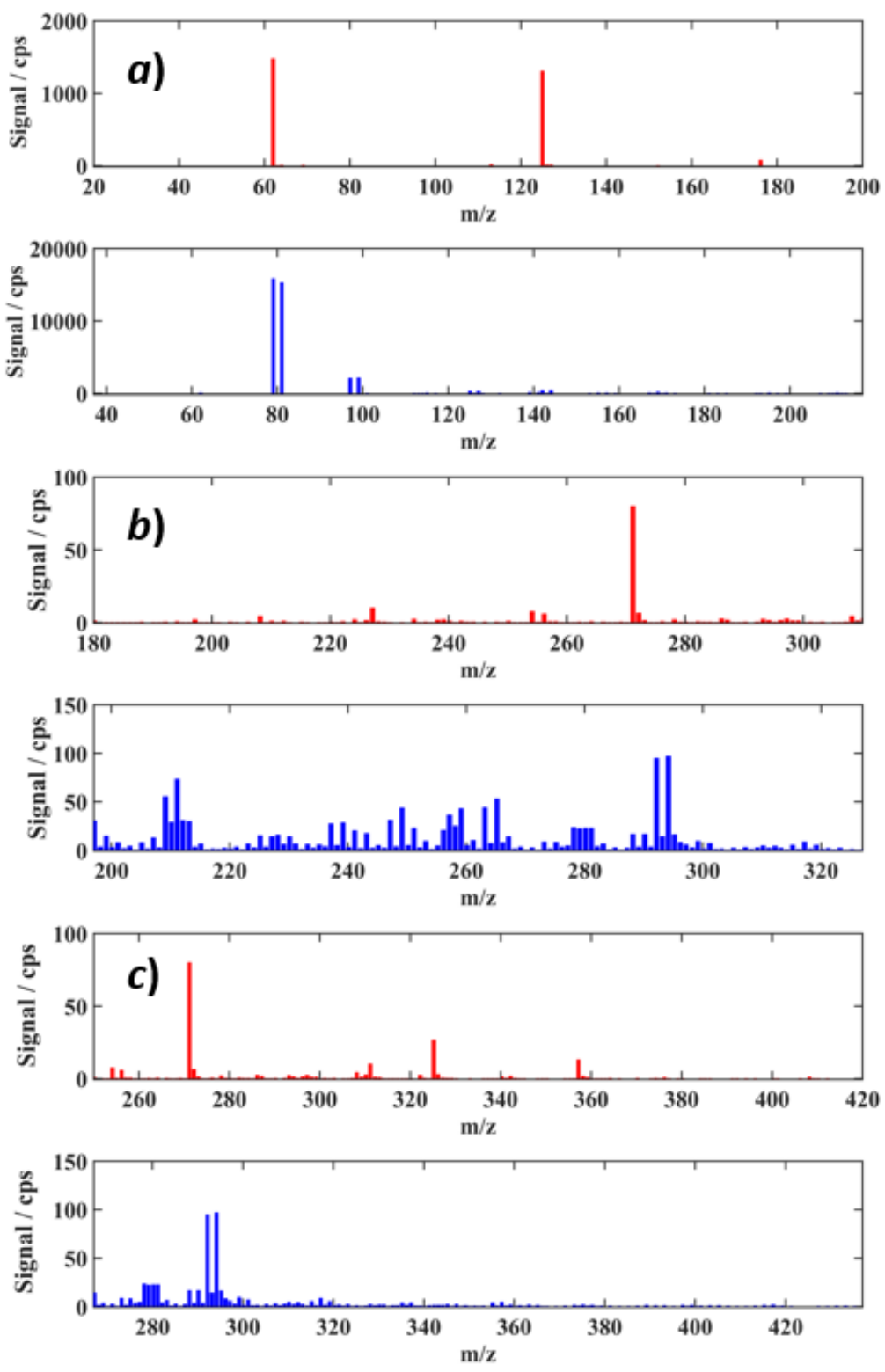

Figure S2 Example spectra obtained from cyclohexene ozonolysis experiments in both ion modes shown with a common product mass axis, i.e., the $\mathrm{Br}^{-}$spectrum is displaced by $17 \mathrm{Th}$ (=difference between reagent ion $\mathrm{Br}^{-}$and $\mathrm{NO}_{3}{ }^{-}$masses) to overlap the same composition products horizontally. Upper panels (red) show nitrate spectra and lower panels (blue) bromide spectra. $\boldsymbol{a}$ ) Illustrates the reagent ion peaks, $\boldsymbol{b}$ ) the monomer range (i.e., oxidation products which have the same number or less carbon atoms than cyclohexene), and $c$ ) the dimer range (i.e., oxidation products with about two times the carbon number of cyclohexene), respectively.

\section{S6 Organic ion peaks devoid of the reagent ion}

Several organic product ions (i.e., ionized products observed without the adduct forming reagent ion) were detected with both ionization modes. Whereas the $\mathrm{NO}_{3}{ }^{-}$only deprotonates few of the strongest inorganic acids (e.g., $\mathrm{H}_{2} \mathrm{SO}_{4}$ and $\mathrm{HIO}_{3}$ ) and a collection of dicarboxylic acids (e.g., adipic acid, $\mathrm{C}_{6} \mathrm{H}_{10} \mathrm{O}_{4}$ ), bromide ionization results in significantly more organic ions as evident from Figure S3. The observed product ion compositions indicate deprotonation by $\mathrm{Br}^{-}$ as the most likely source for these species. However, dehydroxylation of peroxy acids by $\mathrm{Br}^{*} \mathrm{H}_{2} \mathrm{O}^{-}$could be expected in analogy to $\mathrm{I}^{*} \mathrm{H}_{2} \mathrm{O}^{-}$(Mielke et al., 2012; Iyer et al., 2017). While the current purely experimental approach does not give insight into the mechanism of generation of these organic ions, it is obvious they are much more prevalent with $\mathrm{Br}^{-}$than with $\mathrm{NO}_{3}{ }^{-}$ionization. 

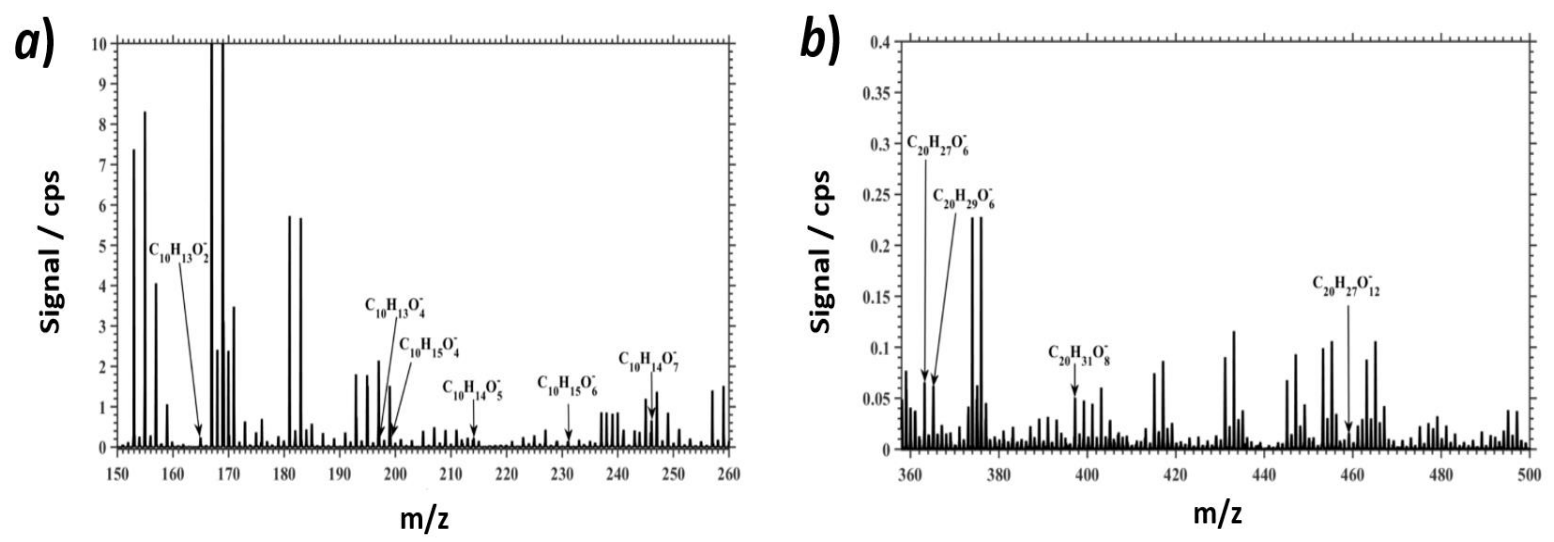

Figure S3 Examples of organic ion peaks detected during $\alpha$-pinene ozonolysis experiment applying bromide ionization. Organic ion peaks were observed in both $\boldsymbol{a}$ ) monomer and $\boldsymbol{b}$ ) dimer mass ranges and were generally minor peaks in the spectra.

\section{References:}

1. Ehn, M., Thornton, J. A., Kleist, E., Sipilä, M., Junninen, H., Pullinen, I., Springer, M., Rubach, F., Tillmann, R., Lee, B., Lopez-Hilfiker, F., Andres, S., Acir, I.-H., Rissanen, M., Jokinen, T., Schobesberger, S., Kangasluoma, J., Kontkanen, J., Nieminen, T., Kurtén, T., Nielsen, L. B., Jørgensen, S., Kjaergaard, H. G., Canagaratna, M., Dal Maso, M., Berndt, T., Petäjä, T., Wahner, A., Kerminen, V.-M., Kulmala, M., Worsnop, D. R., Wildt, J., and Mentel, T. F.: A large source of low-volatility secondary organic aerosol, Nature, 506, 476-479, 2014.

2. Iyer, S., He, X., Hyttinen, N., Kurtén, T., and Rissanen, M. P.: Computational and Experimental Investigation of the Detection of $\mathrm{HO}_{2}$ Radical and the Products of Its Reaction with Cyclohexene Ozonolysis Derived $\mathrm{RO}_{2}$ Radicals by an Iodide-Based Chemical Ionization Mass Spectrometer, J. Phys. Chem. A, 121, 6778-6789, 2017.

3. Jokinen, T., Berndt, T., Makkonen, R., Kerminen, V.-M., Junninen, H., Paasonen, P., Stratmann, F., Herrmann, H., Guenther, A. B., Worsnop, D. R., Kulmala, M., Ehn, M., and Sipilä, M.: Production of extremely low volatile organic compounds from biogenic emissions: Measured yields and atmospheric implications, Proc. Natl. Acad. Sci., 112, 7123-7128, 2015.

4. Kürten, A., Rondo, L., Ehrhart, S., and Curtius, J.: Calibration of a Chemical Ionization Mass Spectrometer for the Measurement of Gaseous Sulfuric Acid, J. Phys. Chem. A, 116, 6375-6386, 2012.

5. Mielke, L. H. and Osthoff, H. D.: On quantitative measurements of peroxycarboxylic nitric anhydride mixing ratios by thermal dissociation chemical ionization mass spectrometry, Int. J. Mass Spectrom., 310, $1-9,2012$.

6. Rissanen, M. P., Kurtén, T., Sipilä, M., Thornton, J. A., Kangasluoma, J., Sarnela, N., Junninen, H., Jørgensen, S., Schallhart, S., Kajos, M. K., Taipale, R., Springer, M., Mentel, T. F., Ruuskanen, T., Petäjä, T., Worsnop, D. R., Kjaergaard, H. G., and Ehn, M.: The formation of highly oxidized multifunctional products in the ozonolysis of cyclohexene, J. Am. Chem. Soc., 136, 15596-15606, 2014. 